\title{
ADjustadesk - An Adjustable Height Desk
}

\author{
Joseph Timothy Foley ${ }^{1, \star}$, Arnór Freyr Símonarson ${ }^{1}$, Hilmar Pór Símonarson ${ }^{1}$, Lúðvík Friðrik Ægisson ${ }^{1}$, and Andri \\ Pór Goethe ${ }^{1}$ \\ ${ }^{1}$ Reykjavik University, Engineering Department, Menntavegur 1, 101 Reykjavik, Iceland
}

\begin{abstract}
It is no wonder that demand of adjustable desks is increasing in the world. People are dealing with long hours sitting down and many have musculoskeletal system problems due to this. Our idea started with this concept but then we applied it for the Reykjavík University workshop which really needs better facilities to keep your laptop and other equipment out of harm's way while working on projects. Our idea is to make an affordable adjustable desk that is suitable for a workshop environment. It will only be mechanical, unlike most desks which are driven by electrical motors. To reduce the gravitational force of the desk we will use gas struts, this will give the desk more flowing motion. The desk met all our requirements. After building the desk we tested it and can withstand $200 \mathrm{~kg}$ on the top and can be pushed from all sides with $50 \mathrm{~kg}$ without flexing. It slides up and down with smoothly and locks in position without any problems.
\end{abstract}

\section{Introduction}

With so many advances in technology, our lifestyles are changing, and as a result, we are spending a lot more time sitting down, which is also called "being sedentary". We sit while driving to school, all day in school, doing homework after school, and in front of the TV at home [1]. Research on physical activity has mainly focused on time adults do intensive exercise, 30 minutes a day is normally the target. However recent studies highlight the importance of focusing on the balance of light intensity exercises and sedentary. One of the concern after this new research was how to reduce or break up prolonged sitting time. This can help to reduce your risk of developing heart disease, diabetes cardiovascular disease, and other prevalent chronic health problems. This will also increase your metabolism which will help to stay in shape [2].

With this in mind, we wanted to design a robust adjustable desk for the Reykjavik University workshop. The height of the desk will be adjusted by man power with the help of a gas strut which will make it feel like it's floating. The problem is that the workshop does not have many places to work at and not much money to improve it, so we wanted to make that improvement possible. Our desk will be a step toward a better workshop and that is our goal. Another thing to consider is the effect sitting has on our musculoskeletal system and adjustable desk will counteract the long hours a student spends sitting down. The prototype will cost around 40000 ISK (379 USD) when it's ready and that is considerably lower price than other manufacturers offer, as can be seen in Section 1.1. When the desk will go in production the aim is to sell it for around

^e-mail: foley@ru.is
45000 ISK (425 USD) since then the manufacturing labor will not be volunteer work anymore.

Axiomatic design was used to develop the design for the AdjustaDesk from customer needs to functional requirements and then design parameters. Axiomatic design is a good method to use in designing since it helps in keeping things simpler and making the design work every time.

\subsection{Background}

During the 18th and 19th centuries standing while working was desired because it thought that it would increase productivity. It was extremely popular and was a sign of prestige and wealth [3]. Indeed many great minds worked at standing desks, such as Stan Lee the famous comicbook author and creator of the Marvel-Universe. A muchcirculated photo of him writing in his back yard bears this caption: "Always wrote standing up — good for the Figure - and always faced the sun - good for the suntan!" [4]. We grouped adjustable height desks (AHD) into categories, each with advantages and disadvantages:

Set-up AHD: usually has a set of pins or an adjustable screw to change the height when the desk is being put together.

Crank AHD: uses a crank handle attached to a powerscrew to adjust the height.

Counterbalanced AHD: uses levers or pulleys and weights to change the heights.

Spring-loaded and Pneumatic AHD: use a compressed spring (or gas-spring) to reduce the effort needed by the user to change the height to preset values. A gas-spring may have a valve to allow the user to set the force or displacement value. 


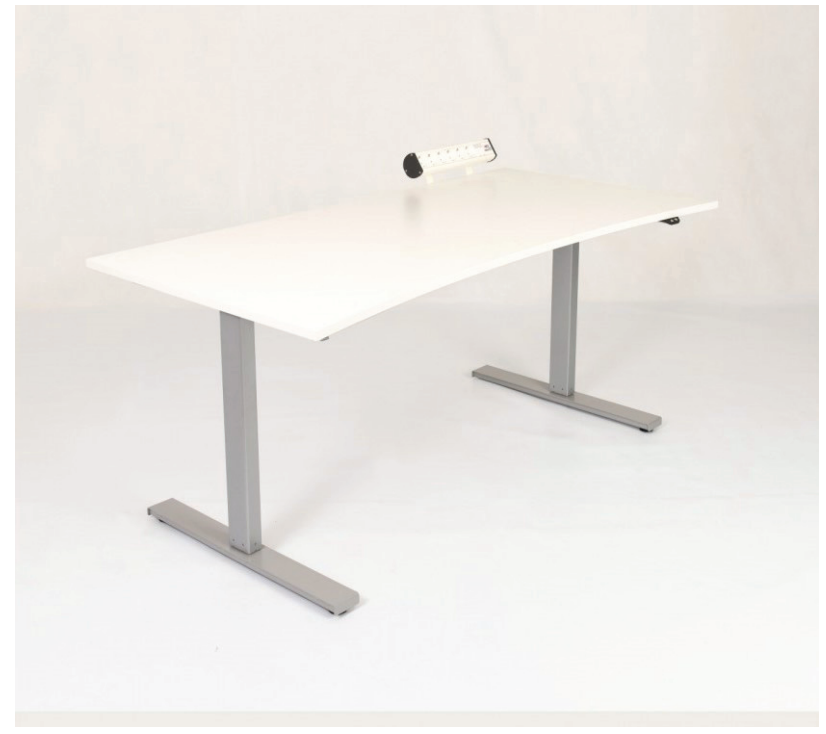

Fig. 1. Electric adjustable desk from Ergolift [6]. Notice the AC mains access module on the top.

Electric AHD: have a motor that engages the desk height mechanism, often a power-screw.

The Set-up AHD wouldn't be changed after setup, its low cost and easy to assemble but not adjustable in everyday use. A Crank AHD is easy to use and cost efficient but can be hard to raise if there is heavy equipment on it. Counterbalanced, spring loaded or pneumatic AHD can be quickly adjusted but can only handle low weights, usually up to $50 \mathrm{~kg}$. Electric AHDs are the easiest to use but the main drawback is the high cost.

Alternatively, there are adjustable height accessories i.e. Miscellaneous AHD for existing desks, often for the keyboard, mouse, and monitor. They are relatively cheap but their usage is limited [5]. Similar products have been made by various companies like Ergolift and Prima but they both use an electric motor to do the lifting. We will be using gas struts to do the main lifting so that the part that moves up/down should be almost weightless when not loaded. The idea is when you put stuff on the desk and lift/lower it, you should only be lifting the extra weight on the desk since the desk itself is "weightless" because of the gas struts. This is a one of a kind desk as we could not find the same concept for sale on-line. Our goal is to make this desk cheaper with the same functionality for the customer. Similar Ergolift desk costs 84900 ISK (802 USD) [6] with no accessories and the Prima desk costs 62900 ISK (594 USD) [7] with no accessories. A desk that is already in Reykjavik University but not suitable for the workshop can be seen in Figure 3 .

\section{Design}

The concept came from members of the designer's group because they had been having back pain and they had been thinking of a practical solution and wanted to make their own desk for a low cost because they are poor students.

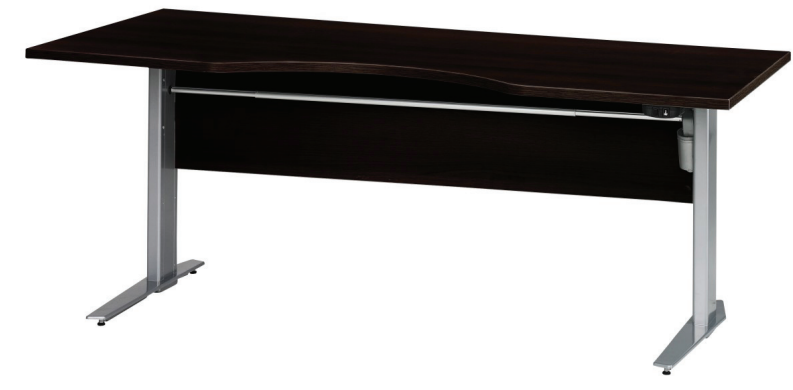

Fig. 2. Electric adjustable desk from Prima [7].

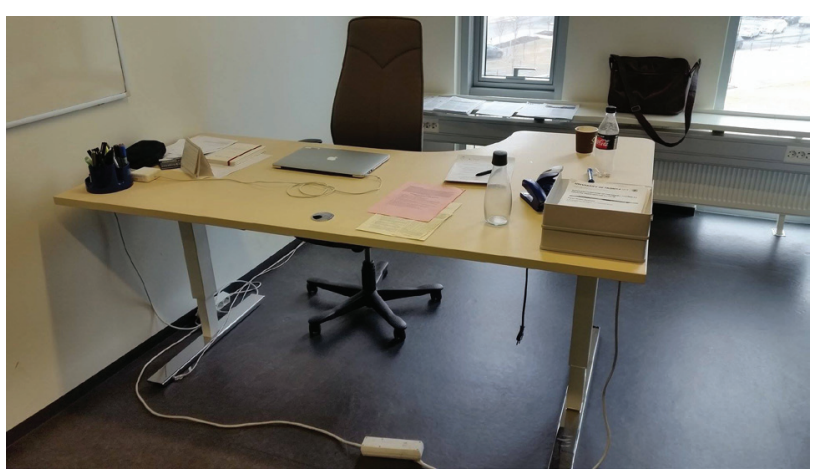

Fig. 3. Existing electric adjustable desk used at Reykjavik University.

The back pain is due to excessive sitting which is common for students and people working in office jobs.

\subsection{Design process}

The Axiomatic design theory is a system of using matrix methods to analyze the transformation of Customer Needs into Functional Requirements and to find a Design parameter to satisfy these conditions. Axiomatic design focuses on Functional Requirements and Design Parameters (FRs and DPs) and the connections between them, through a process of mapping between the functional domain to the physical domain [8].

There are two design axioms that distinguish a great design. Axiom 1 involves the relationship between functions and physical variables and Axiom 2 involves with the complexity of the design, what parts to use and etc. These axioms can be stated in a variety of semantically equivalent forms. The declarative form of the axioms is the following [9]:

- Axiom 1 The independence Axiom Maintain the independence of FRs

- Axiom 2 The information Axiom Minimize the information content of the design

Axiom 1 states that during any design process, we go from the FRs in the functional domain with the DPs in the physical domain. The mapping must be conducted so 
that a particular Design parameter Functional requirement must affect only its referent Functional requirement [9]. When this objective is achieved, the design matrix will be diagonal as each DP relates to only one FR with no coupling, this is called uncoupled matrix. When the matrix is not uncoupled it can be either decoupled or coupled. Decoupled matrix is path dependent, meaning that the sequence of implementation of the DPs is critical and starts with the DP that affects most FRs, followed by the DP that affects the second most number of FRs and so on. When off-diagonal elements exist the matrix cannot be organized to a triangular form, this is called coupled [8]. Axiom 2 states that the design with the least information content is the finest design. When multiple options of DPs have been developed these axioms can be used to choose the finest set of DPs. You want to choose DPs to provide the least coupling preferably no coupling while preserving minimum information content [8].

The Axiomatic Design process of the adjustable desk started by analyzing the customer's needs then processing them into functional requirements. Proposed concepts were worked out, followed by further research analysis of the proposed solutions. The final step was to compare the design to the customer needs and make sure every single need was met.

\subsection{Customer attributes}

At the beginning of the design, we discussed what we as students wanted for this desk. After some discussion and research, we assumed the target customer to be workshop owners and created our list of customer needs accordingly.

Customer needs regarding the desk: $\mathrm{CN}_{1}$ : Adjustable desk that suits people in common sizes.

$\mathrm{CN}_{2}$ : The desk has to be steady so you can lean on it while working.

$\mathrm{CN}_{3}$ : It should be affordable

$\mathrm{CN}_{4}$ : It should have electrical sockets

$\mathrm{CN}_{5}$ : The top panel should endure hammer beatings and fluids without deteriorating.

\subsection{Constraints}

Constraints affect the design though they are not functional requirements. Constraint number one was set by the University as our budget and constraint number two was set by us to keep within the budget.

Constraints regarding the desk:

$\mathrm{C}_{1}$ : Total cost can not exceed 40000 ISK (378 USD).

$\mathrm{C}_{2}$ : Can be manufactured in the RU workshop.

\subsection{Functional requirements}

Functional Requirements must begin with an action verb. FR's must be able to be validated so when the construction is done some experiments will be done to confirm if the FR's are met [9].
Functional Requirements regarding the desk:

$\mathrm{FR}_{1}$ : Positions a work surface vertically

$\mathrm{FR}_{2}$ : Stays stable when worked on

$\mathrm{FR}_{3}$ : Locks in position

$\mathrm{FR}_{4}$ : Powers appliances

$\mathrm{FR}_{5}$ : Endures hammer strikes and fluid spills on surface

\subsection{Design parameters}

Once we know our FR's for the desk we can find our DP's to satisfy our FR's. DP's are in the physical domain so they start with a noun [9].

Design parameters regarding the desk:

$\mathrm{DP}_{1}$ : Man power with help of gas strut

$\mathrm{DP}_{2}$ : Stiff materials and wide base

$\mathrm{DP}_{3}$ : Pull pin locks the desk

$\mathrm{DP}_{4}$ : Sockets mounted on desk

$\mathrm{DP}_{5}$ : Steel sheet metal to cover the top panel

\subsection{Design matrix}

Now with the FR-DP mapping completed the next step is to build the design matrix. The design matrix shows how the DPs satisfy the corresponding FRs. It is a visual representation of how much each FR is affected by each DP. An uncoupled matrix is purely diagonal and that is what you should aim for because then each DP only affects one FR. Our matrix is decoupled because both $\mathrm{DP}_{1}$ and $\mathrm{DP}_{3}$ affect $\mathrm{FR}_{1}$ because to lift $\left(\mathrm{DP}_{1}\right)$ the desk the pull pins $\left(\mathrm{DP}_{3}\right)$ have to be pulled out. We could not conceive of a less coupled solution [9].

$$
\left\{\begin{array}{l}
F R_{1} \\
F R_{2} \\
F R_{3} \\
F R_{4} \\
F R_{5}
\end{array}\right\}=\left[\begin{array}{ccccc}
X & 0 & X & 0 & 0 \\
0 & X & 0 & 0 & 0 \\
0 & 0 & X & 0 & 0 \\
0 & 0 & 0 & X & 0 \\
0 & 0 & 0 & 0 & X
\end{array}\right]\left\{\begin{array}{l}
D P_{1} \\
D P_{2} \\
D P_{3} \\
D P_{4} \\
D P_{5}
\end{array}\right\}
$$

\subsection{Description of the design}

Throughout the design, we had the principle of symmetry in mind which is closely related to stability. Stability of one of our FR's so it is important to keep in mind. Moments are not created and the system only expands but does not bend. According to Abbe's principle bending creates angular deformations which are amplified with distance, and hence are generally to be avoided [10]. This relates directly to Nam P. Suh's corollary 5 which implies the use of symmetry when it's consistent with the FRs and constraints [9]. For the sliding guidance, we used SaintVenant's Principle for jamming. It says that the length of the sliding interface should be 3-5 times the diameter in our case [10].

The final frame is assembled out of 2 separate frames connected by hydraulic gas struts. The gas struts are there to counter the weight of the part of the desk that moves 


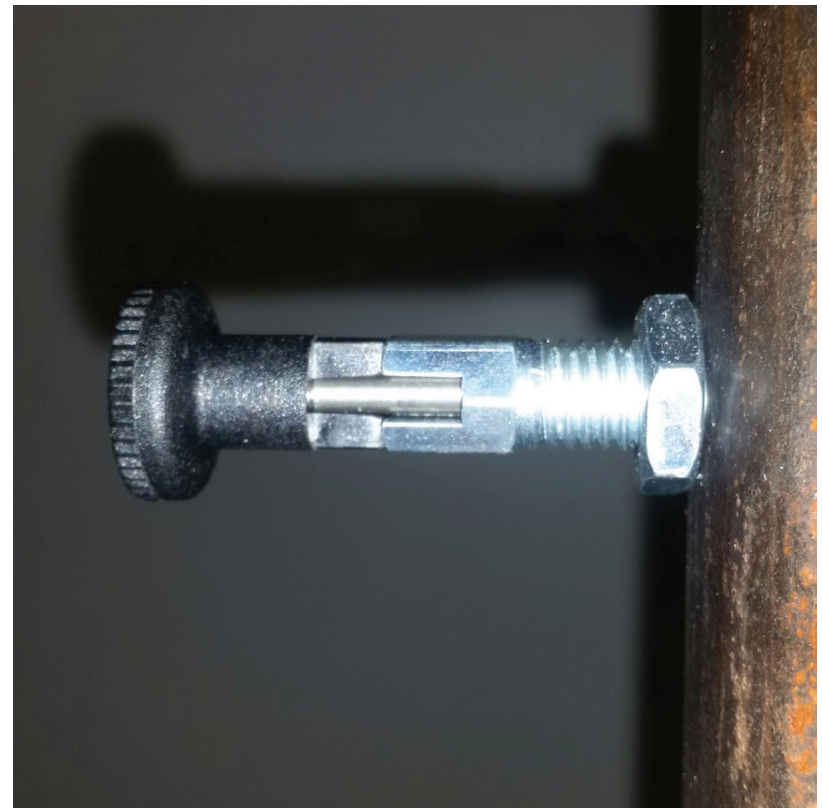

Fig. 4. Pull pin in unlocked position.

up/down. To find the type that we chose we had to calculate how much force would be needed to make the top panel "weightless". To lock the desk in the right position there are indexing plungers (pull pins) on each leg see Figure 4. And to unlock it you simply pull them out and twist them 90 so it stays out while you are adjusting the height, they will be mounted onto of the outer leg pipe. To keep the desk on track the upper frame slides into the bottom frame. The outer pipe will have the indexing plunger mounted at the top and the inner pipe will have holes in it so it can be locked in various positions. The smaller one will go into the larger one with a $1 \mathrm{~mm}$ clearance at all sides. They will work as guides and support. The square tubings used to connect the pipes are $80 \times 20 \times 2 \mathrm{~mm}$, that will be stiff enough. And $20 \times 30 \times 2 \mathrm{~mm}$ profiles to strengthen the frame goes under the desk to connect the legs. To strengthen the overall desk a stiffening bracket was built and welded between the two legs of the bottom frame, this was made from the same pipe as the inner pipes of the legs, can be seen in Figure 7 and 8. The top panel is $2 \times 1 \mathrm{~m}$ and build out of $21 \mathrm{~mm}$ thick plywood board. It will be bolted to the upper frame. To strengthen and protect the surface from wear and tear a panel a $1 \mathrm{~mm}$ steel sheet will be glued to the plywood. The design can be seen in Figure 8 and all relevant dimensions in Figures 5, 6 and 7 Under the desk, located in the middle of the long side, at both sided, there will be double electrical sockets connected together. A cable coming from one of the sockets with a length of $5 \mathrm{~m}$ will be used to connect the desk to a wall socket.

\subsection{Assumptions}

We assume that the density of the plywood to be $600 \mathrm{~kg} \mathrm{~m}^{-2}$, and of the steel to be $7800 \mathrm{~kg} \mathrm{~m}^{-2}$. The desk will be located inside, so rusting and corrosion will not oc-

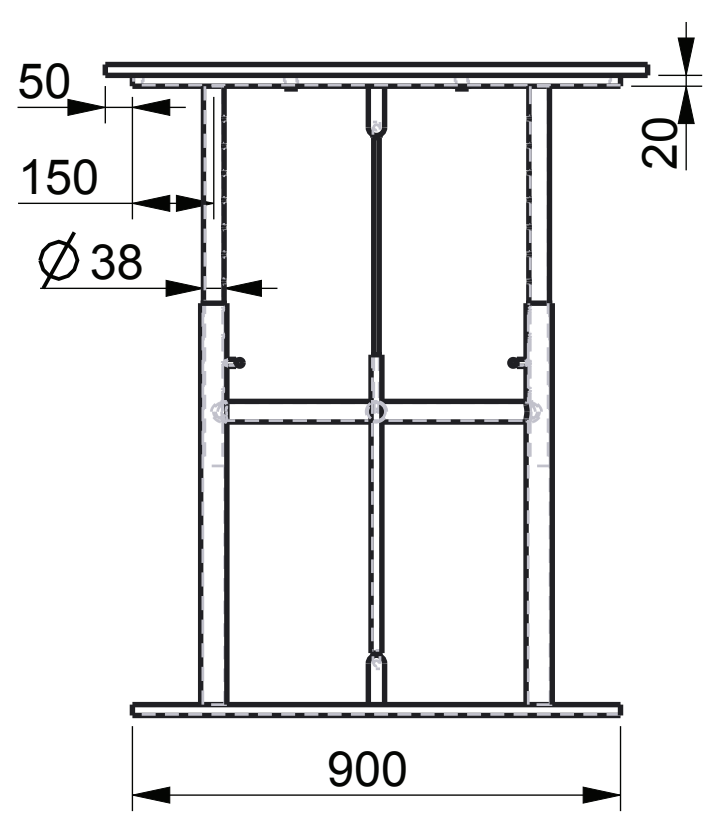

Fig. 5. Front view of the desk from Creo, all dimensions in $\mathrm{mm}$.

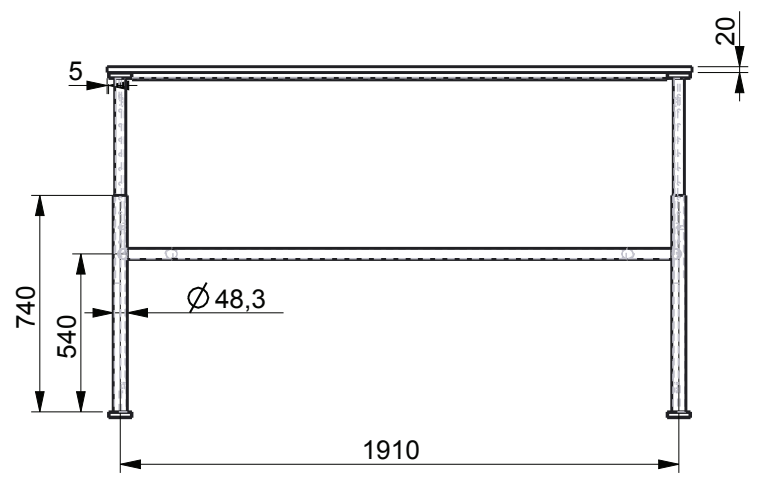

Fig. 6. Side view of the desk from Creo, all dimensions in $\mathrm{mm}$.

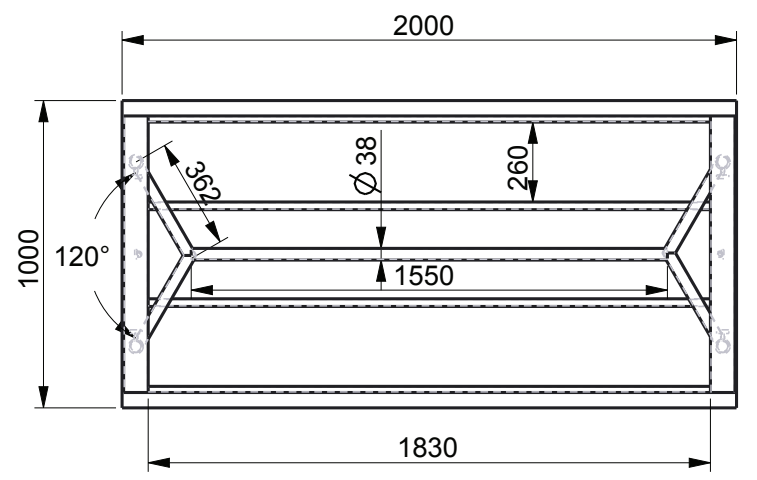

Fig. 7. Top view of the desk from Creo, all dimensions in $\mathrm{mm}$. 
Table 1. Information on flat materials used in construction for calculating the mass.

\begin{tabular}{lrrr}
\hline Material & $\begin{array}{l}\text { Density } \\
{\left[\mathrm{kg} \mathrm{m}^{-2}\right]}\end{array}$ & $\begin{array}{l}\text { Volume } \\
{\left[\mathrm{m}^{3}\right]}\end{array}$ & $\begin{array}{l}\text { Mass } \\
{[\mathrm{kg}]}\end{array}$ \\
\hline Plywood & 600 & 0.040 & 24.0 \\
Sheet metal & 7800 & 0.002 & 15.6 \\
\hline
\end{tabular}

Table 2. Beam specifications for calculating the mass.

\begin{tabular}{lrrr}
\hline Beam & & $\begin{array}{r}\text { Length } \\
{[\mathrm{m}]}\end{array}$ & $\begin{array}{r}\text { Mass } \\
{[\mathrm{kg}]}\end{array}$ \\
\hline $80 \times \mathrm{mm} 20$ profile & 3.00 & 2 & 6.0 \\
$20 \times \mathrm{mm} 20$ profile & 1.13 & 4 & 4.5 \\
$38 \times \mathrm{mm} 2.6$ tubing & 2.23 & 3 & 6.6 \\
\hline
\end{tabular}

cur. The floor should be fairly level. Placing objects on the desk should be done with common sense and not dropped on it with the sharp corner down [11].

\subsection{Calculations}

We estimated the amount of material that will be used and calculate the weight from the density and volume of the material to choose the correct gas struts. Mass per lengthmeter is given in the catalog for the steel beams. Since the gas struts only lift the top part of the desk the calculations only take the top part of the desk into consideration.

$$
m=\mu l
$$

Equation 2 [12] is to calculate the mass of the beams in the top part of the desk where $m=$ mass $[\mathrm{kg}], l=$ total length [m] and $\mu=$ mass per unit length $\left[\mathrm{kg} \mathrm{m}^{-1}\right]$

$$
m=\rho V=\rho l w h
$$

Equation 3 [12] is to calculate the mass of the plywood and steel sheet metal where $m=$ mass $[\mathrm{kg}], \rho=$ density $\left[\mathrm{kg} / \mathrm{m}^{3}\right]$, $V=$ volume $\left[\mathrm{m}^{3}\right], l=$ length $[\mathrm{m}], w=$ width $[\mathrm{m}]$ and $h=$ height $[m]$.

The total mass of the top part of the desk is estimated to be $56.7 \mathrm{~kg}$ or around $550 \mathrm{~N}$ thus gas struts were chosen for $600 \mathrm{~N}$.

\section{Experiments}

Now that the design was complete, it was time to test if the prototype would meet the specified requirements. Due to the large range of possible uses, the focus was on qualitative usage tests:

- basic structural tests

- stability tests

- impact tests
Table 3. Tests performed on the adjustable desk prototype.

\begin{tabular}{lr}
\hline Test & Load $[\mathrm{kg}]$ \\
\hline Structural Strength & 200 \\
Sideways Load & 50 \\
Frontal Load & 50 \\
\hline
\end{tabular}

- ease-of-adjustment tests

- surface compatibility tests

The structural test applied $200 \mathrm{~kg}$ on top of the desk without significant deflection. Then a force of $50 \mathrm{~kg}$ was applied on the ends when in highest position to test for stability, on every side. Thirdly there was a test to see if the gas struts worked like they were supposed to, by making it easier to lift and lower the height of the desk. There was also a test to see if the desk was able to withstand heavy blows on top of it e.g. from a hammer. The first test was performed by Arnór and Andri, combined weight of about $200 \mathrm{~kg}$, walking around on top of the desk without it permanently deforming. In the second test, they leaned on the desk applying $50 \mathrm{~kg}$ combined. We know the forces by using a scale to measure their weight, both standing up straight and leaning on the scale with the same angle as they did on the desk. There was not an opportunity to test if the gas strut system worked due to significant delays in shipping. Although we couldn't test the gas struts, we tested the movement of the desk by hand and it slid smoothly up and down. The test for heavy blows was performed by hitting a steel beam on the desk with a $2 \mathrm{~kg}$ sledgehammer. The results are that the desk is strong enough to withstand $200 \mathrm{~kg}$ workload and is also robust enough not to wobble when sideway force is applied. The sheet metal on top of the desk makes it able to withstand a hammering and fluid spills which are easy to clean. From these tests, we make that assertion that this desk is robust enough to be used in the workshop at Reykjavik University.

\section{Result and discussion}

The desk met all FRs in Section 2.4: it slid easily enough up and down and was extremely stable. The tests listed in Section 3 were performed and the desk met all the requirements except for the assisted lift test due to the omission of the gas springs. That said, the desk moved up and down the way it should by hand and when the springs arrive, we are confident that they will be sufficient. The loads for the tests can be seen in table 3 . The desk held up well with $200 \mathrm{~kg}$ on it and was stable when leaned on from the side it didn't wobble or move around. The top panel came out great with the sheet metal on top of the plywood, robust enough with a tough durable surface.

This design could be developed further by adding more customizations such as the electrical sockets. For serious workshop usage it would be better to have an adjustable force gas strut to adjust the force needed to lift or lower the desk. This design allocated 3000 ISK for the fixed 


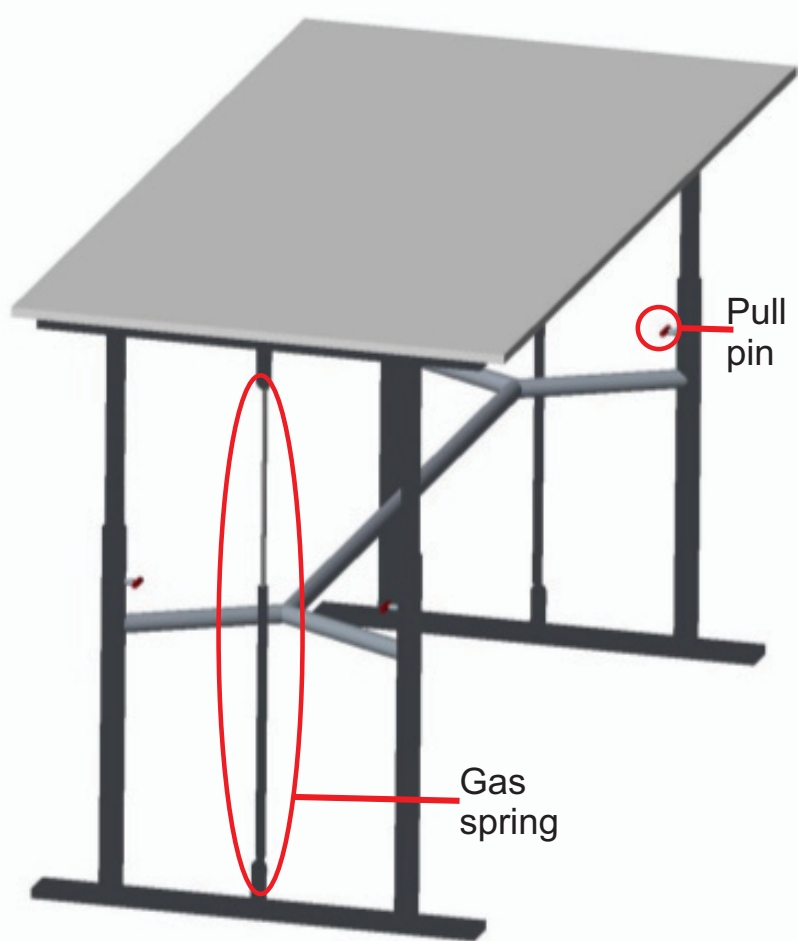

Fig. 8. Final design view of the desk from Creo.

gas struts instead of more than double that cost for the adjustable struts. If the adjustable gas strut were to be added to the desk, the range of working weights would be increased.

There were some difficulties in the manufacture of the desk prototype. When the steel parts were welded together, there was unexpected amounts of warping, so some parts had to be cut loose and re-welded. Future designs would employ square profiles with fasteners to join together the frame. To fit the three pipes together in the inner frame they had to be notched: square profile would not require this operation.

\section{Conclusion}

The ADjustadesk prototype was a success: as can be seen in Section 3 the desk did pass all the relevant tests. We tested if it is possible to adjust the height of the desk [FR 1 and that works very well considering that the gas struts are missing, because of reasons listed in Section 3. We tested for stability $\left[\mathrm{FR}_{2}\right]$ by applying force on the sides of the desk the result was that we did not experience an excessive displacement in any direction. The locking of the desk in a specific height $\mathrm{FR}_{3}$ was tested simultaneously as tests for $\left[\mathrm{FR}_{2}\right]$ by locking the desk in place while we performed the structural tested. The ability to power appliances $\left[\mathrm{FR}_{4}\right]$ is two electrical sockets fasten under the desk with a 5-meter electrical cable which makes it possible to have the desk centrally located in the room. The desk height intervals turned out great for both sitting and standing at the desk as can be seen in Figure 9 and Figure 10 This adjustable desk highlights the strengths of Axiomatic Design: we gained

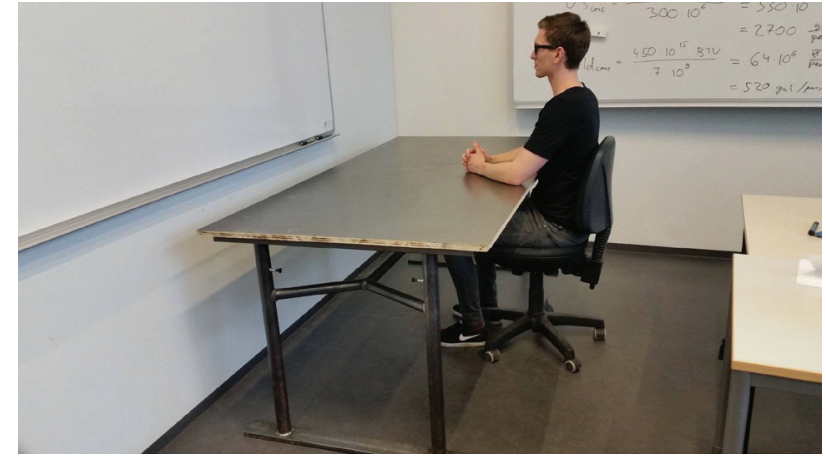

Fig. 9. Test subject sitting at the desk.

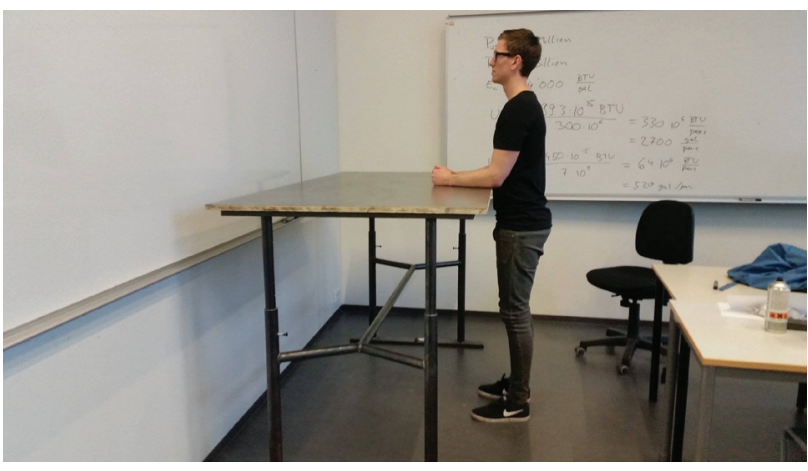

Fig. 10. Test subject standing at the desk.

an understanding of the interaction between each of the elements and worked hard to keep them from interfering from each other. Ultimately, this and clear Functional Requirements are what made this project successful.

\section{References}

[1] SA Health, The risk of sitting too much, http://www. sahealth.sa.gov.au/wps/ wcm/connect/public+content/sa+health+ internet/healthy+living/is+your+health+ at+risk/the+risk+of+sitting+too+much

[2] N. Owen, A. Bauman, W. Brown, Too much sitting: a novel and important predictor of chronic disease risk?, BMJ Journal 43 (2009)

[3] J. Kelly, History of standing desks (2012), https://notsitting.com/standing-desks/ general-info/history/

[4] L. Swanson, The definitive guid to actual famous standing desk users (2016), http://well9to5. com/famous-standing-desk-users /

[5] Height Adjustable Desk Advise, What are the different types of heigth adustable desks ((n.d.)), http: //www.heightadjustabledeskadvice. com/types-of-height-adjustable-desks/

[6] skrifstofa.is, Ergolift rafmagnsbord ((n.d.)), https://www.skrifstofa. is/bord/rafmagnsskrifbord/ ergolift-idt-rafmagnsbord 
[7] egskrifstofuhúsgögn.is, Prima rafmagnsbord ((n.d.)), http://www. xn--egskrifstofuhsggn-e@b7e.is/bord/ skrifbord/prima-rafmagnsbord

[8] D.S. Cochran, J.T. Foley, Z. Bi, Use of the Manufacturing System Design Decomposition for Comparative Analysis and Effective Design of Production Systems, International Journal of Production Research p. 24 (2016)

[9] N.P. Suh, The Principles of Design (Oxford University Press, 1990)
[10] A.H. Slocum, FUNdaMENTALS of Design (Massachusetts Institute of Technology, 2007), http://pergatory.mit.edu/resources/ FUNdaMENTALS.html

[11] The Engineering Toolbox, Density of solids (2017), http: //www . engineeringtoolbox.com/ density-solids-d_1265.html

[12] H.D. Young, R.A. Freedman, Sears E Zemansky's University Physics with Modern Physics 13th edition (Jim Smith, 2012) 